\title{
CLASSIFICATION OF STRUCTURALLY WEAK RURAL REGIONS: APPLICATION OF A RURAL DEVELOPMENT INDEX FOR AUSTRIA AND PORTUGAL
}

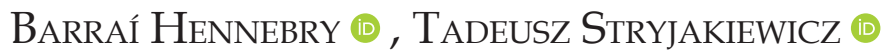 \\ Faculty of Human Geography and Planning, Adam Mickiewicz University, Poznań, Poland
}

Manuscript received: March 26, 2020

Revised version: May 6, 2020

\begin{abstract}
Hennebry B., StryJAKiewicz T., 2020. Classification of structurally weak rural regions: Application of a rural development index for Austria and Portugal. Quaestiones Geographicae 39(2), Bogucki Wydawnictwo Naukowe, Poznań, pp. 5-14. 6 tables, 5 figs.

AвSTRACT: This paper aims to analyse to what extent the level and dynamics of development of rural regions located in two firmly different countries, Austria and Portugal, differ. In order to do this, an index to measure the 'structural strength' of rural regions was created. This index is a more holistic measure of socio-economic development than the traditional GDP per capita. After the identification of structurally weak regions in both Austria and Portugal, the paper compares them in the context of challenges faced by such regions.
\end{abstract}

KEYWORDS: rural development, regional disparities, TOPSIS method, composite index, Austria, Portugal

Corresponding author: Hennebry B., Faculty of Human Geography and Planning, Adam Mickiewicz University, Poznań, ul. B. Krygowskiego 10, 61-680 Poznań, Poland; e-mail: hennebry@amu.edu.pl

\section{Introduction}

Structural weakness is a problem for many rural regions in Europe. However, its nature and the strategies of coping with it are different. Therefore, it is very important to make comparative studies in order to find the best ways to solve the problem. The starting point of this paper is an attempt to find an appropriate measure in order to identify structurally weak rural regions. In the present paper, we have chosen two countries, Austria and Portugal, for such an analysis. Both are located in Europe but present different natural conditions, types of rural economy and institutional settings. Both countries have faced the issue of regionalisation. Austria's issue with regionalisation can largely be seen as being caused by historical factors, while Portugal's regionalisation is largely geographical in nature.

During the Habsburg monarchy, there were distinct regional disparities in Austria between the industrial west and agricultural east (Good 1981). These disparities continued after the collapse of the monarchy and were accentuated in the post WW2 era as the eastern territories were occupied by Soviet forces until 1955. This meant that these regions were slower to avail of US funds and investments. Tödtling (1983) classified 'peripheral less-developed areas' in Austria based on their degree of accessibility and level of development. He found that the peripheral less-developed areas 'consist mainly of northern, eastern and southern border areas (bordering the Eastern European countries) and some mountain 


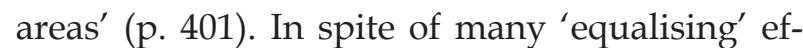
forts of the Austrian government, taking advantage of the EU cohesion funds, this statement is still valid at present (cf. Kilper 2009; Wink et al. 2016; Neufeld 2017). The border mountain areas seem particularly affected.

The regional disparities in Portugal result from a 'littoralisation' process as wealth is concentrated in coastal regions, mainly along the Lisbon-Porto axis and the Algarve, while the inland regions have remained neglected and underdeveloped. This has been caused by the 'absence of transfers of investments and of responsibilities to the peripheral zones and the impoverishment of the countryside, solely for the benefit of industrial growth in an urban environment without any true sharing or distribution' (Mayer 1981: 344). Lois-González (2007: 78), from analysing a Portuguese geography textbook, came to the conclusion that 'Lisbon, the capital, is seen as the centre of the country, although the spotlight is cast on the Lisbon-Porto axis concentrating all the wealth, dynamism and population. There are frequent allusions to a littoralization process, the polarization of growth in coastal areas. Finally, the islands and the interior border areas are clearly marked as peripheral territories'.

To understand better the regional disparities, especially among rural regions, it is important to analyse them on a deeper level than just gross domestic product (GDP). Recently, there has been an emphasis on the need to move beyond the use of GDP as the sole measure of economic success (Stiglitz et al. 2018). GDP is seen as one-dimensional and is unable to capture the complexity of development. Hence, the use of indexes such as the United Nations Human Development Index (HDI). There has also been an increase in academics developing synthetic indexes in an attempt to capture the complexity of economic development. A good example is Jakubowski's (2018) creation of a regional development index to measure 'the multifaceted nature of development processes and cohesion policy' (p. 31).

So far, there have been sparse attempts to develop an index capturing the nature of rural development. Michalek and Zarnekow (2012) created and applied a rural development index for rural regions in Poland and Slovakia. There are two weaknesses in their index. Firstly, the indicators used to create the index differ for both countries. Secondly, the indicators used for creating the index do not remain constant over time. These weaknesses mean that international comparisons and comparisons over time are not accurate. Abreu et al. (2019) developed a rural development index for Portuguese municipalities. However, the indicators they used were from the Portuguese census, which is done every five years. This means that the index cannot be measured on an annual basis.

The research presented in this paper aims to fill the gap in the literature by following OECD's Handbook on constructing composite indicators (2008) to develop an index that captures the structural strength of rural regions (the SSRR index). This index is created in a way that will allow for it to be measured annually and which allows for international comparisons. The paper is structured as follows: section 2 will describe the theoretical framework for understanding rural development, section 3 will explain the methodology and data used in constructing the index. Section 4 will analyse the results of applying the index for Austria and Portugal (i.e. at the national level), while section 5 will analyse the results for one structurally weak region selected from each country (i.e. at the regional level). Section 6 will offer a discussion on the results and some conclusions.

\section{Theoretical framework}

Rural regions are often seen as lagging or economically weak, with less opportunities for the younger population. The OECD (2006) has labelled this as the 'circle of declining rural regions', whereby a low population density means a lack of critical mass for services and infrastructure, low rates of business creation and fewer job opportunities (Fig. 1). However, not all rural regions are trapped in this circle of decline. In fact, some rural regions are thriving and seeing an increase in population and productivity.

A formal model for rural development and how some rural regions could be trapped in a circle of decline is provided by the work of Petrick (2013). He uses evolutionary game theory to model rural development as the increasing realisation over time of gains from interaction by rural stakeholders' (p. 707). The model shows that there are 
two Nash equilibrium points for rural regions: one equilibrium point is where the rural region is trapped in decline and the other equilibrium point is where the rural region is thriving. For this model, the rural population is divided into two groups of stakeholders, mobile and immobile, and each group has two potential strategies.

The mobile group is characterised as being the younger, more educated population. This group has less restrictive ties to the rural regions (no dependent relatives, and they don't own property or have other investments in the region). Their education provides them with the possibility of finding employment in an urban region. This group lacks financial security meaning that they are unable to invest in the local economy. This population has two possible strategies; they can stay in the rural region or move to an urban region.

The immobile group is characterised as being the older and less educated population. This group has restrictive ties in the rural region (dependent relatives, or they own property in the rural region), or their skills likely prohibits their potential to seek employment in urban areas (farming, fishing, etc.). This means that their movement out of the rural region is restricted. Unlike the mobile group, however, they do have more financial security, which means that they can invest in the local economy. The two strategies for this group are: they can invest in the local economy or they can abstain from investing.

Table 1 shows the potential results of the coordination game for rural development, where: $Y=$ the net payoff of staying/investing in a thriving

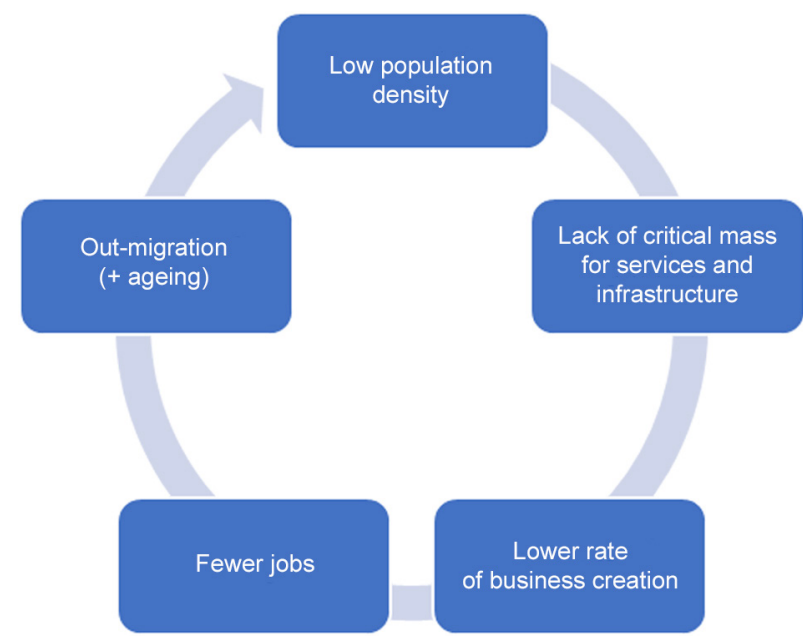

Fig. 1. The circle of declining rural regions. Source: adapted from OECD (2006). rural region, $\mathrm{Wr}=$ the rural wage rate and $\mathrm{Wu}=$ the urban wage rate. It is assumed that $\mathrm{Y}>\mathrm{Wu}>$ $\mathrm{Wr}>0$. There are two Nash equilibrium points, which are presented in bold. A Nash equilibrium point is an outcome to a game where neither player can improve their outcome, assuming that the other player leaves their strategy unchanged (Nash 1951).

Let's address the two unstable outcomes of the game. In the top right corner, we have a situation where the mobile group stays, and the immobile group abstains from investing. This means that both groups earn the rural wage rate. This is unstable as either group could improve their outcome by changing their strategy. The mobile could move and earn the urban wage rate, which is higher than the rural wage rate, or the immobile could invest and earn $Y$, which is higher than the rural wage rate. In the bottom left corner, we have another unstable outcome where the mobile moves to the urban region and the immobile invests. In this outcome, the mobile group earns the urban wage rate and the immobile earns 0 (as there is not enough population remaining in the rural region for the immobile to make a profit from their investment). This is again unstable as either group could improve their outcome by changing their option. The mobile could stay and earn $Y$ or the immobile could abstain from investing and earn the rural wage rate.

There are two equilibrium points in this game. The result in the bottom right corner is an equilibrium point where the rural region is trapped in a 'circle of decline'. In this outcome, the mobile group has moved to the urban region and the immobile has abstained from investing. Neither party can improve their situation by changing their strategy, unless the other party also changes. In this outcome we have what could be seen as a structurally weak rural region, which experiences outmigration, an aging population and lack of investment.

Table 1. The rural coordination game.

\begin{tabular}{|l|c|c|}
\hline & $\begin{array}{c}\text { Immobile invests } \\
\text { locally }\end{array}$ & $\begin{array}{c}\text { Immobile } \\
\text { abstains from } \\
\text { investing }\end{array}$ \\
\hline $\begin{array}{l}\text { Mobile stays in } \\
\text { rural region }\end{array}$ & $\mathbf{Y}, \mathbf{Y}$ & $\mathbf{W r}, \mathbf{W r}$ \\
\hline $\begin{array}{l}\text { Mobile moves to } \\
\text { urban region }\end{array}$ & $\mathbf{W u}, 0$ & $\mathbf{W u}, \mathbf{W r}$ \\
\hline
\end{tabular}

Source: Petrick (2013: 714). 
The other equilibrium outcome is the top left corner. In this outcome, the mobile group stays and the immobile invests, which leads to both parties earning $Y$ (the net payoff for staying/ investing in a thriving rural region). The investment from the immobile group provides opportunities to the mobile group, which incentivises them to stay and the larger population creates the market for the immobile to earn a profit on their investment. In his outcome, we have a thriving rural region, which can be described as a structurally strong rural region. This region will experience a growing population and increasing investment.

The purpose of developing the SSRR index is to capture the complexity of this circle of decline and understand which rural regions are trapped in decline and which are thriving.

\section{Methodology}

Four indicators were chosen to develop the SSRR index in order to measure the structural strength of rural regions. GDP per capita (PPS) and employment rate are used as they represent the strength and productivity of the local economy. Net business creation and crude net migration rate are used as these appear as important indicators in both the OECD's 'circle of declining rural regions' (2006) and Petrick's model of rural development (Petrick 2013). Net business creation is seen as evidence that those with financial means have belief in the stability of the local economy and are willing to invest in it. Out-migration is seen as evidence that the young population don't see a future for themselves in the region and feel the need to leave in order to pursue better opportunities. In-migration on the

Table 2. Indicators used for the SSRR index.

\begin{tabular}{|l|c|c|}
\hline \multicolumn{1}{|c|}{ Indicator } & Calculation & Source \\
\hline $\begin{array}{l}\text { GDP per capi- } \\
\text { ta (PPS) }\end{array}$ & No calculation needed & $\begin{array}{c}\text { Euro- } \\
\text { stat }\end{array}$ \\
\cline { 1 - 2 } $\begin{array}{l}\text { Employment } \\
\text { rate }\end{array}$ & \begin{tabular}{c} 
Number of persons employed \\
\cline { 2 - 3 }
\end{tabular} & $\begin{array}{c}\text { Euro- } \\
\text { Population (15 to 64 years) } \\
\text { stat }\end{array}$ \\
\cline { 1 - 2 } $\begin{array}{l}\text { Net Business } \\
\text { Creation }\end{array}$ & $\begin{array}{c}\text { Births - Deaths of enterprises } \\
\text { Euro- } \\
\text { stat }\end{array}$ \\
\cline { 2 - 3 } $\begin{array}{l}\text { Crude rate of } \\
\text { net migration }\end{array}$ & No calculation needed & $\begin{array}{c}\text { Euro- } \\
\text { stat }\end{array}$ \\
\hline
\end{tabular}

Source: own work. other hand is an indicator that opportunities exist within the region and people are willing to relocate there. A breakdown of the data and the calculation method are presented in Table 2.

In order to create the index, the technique for order preference by similarity to ideal solution (TOPSIS) has been used. This method was developed by Hwaang and Yoon (1981) and was used for creating synthetic indicators for regional development by Pawlewicz et al. (2020) and Malinowski (2019). In our study, the following six steps were followed in order to create the SSRR index:

Step 1: The four indicators mentioned above were normalised. This is necessary in order for the indicators to be comparable. The formula for this is:

$$
r_{i j}=\frac{x_{i j}}{\sqrt{\sum_{i=1}^{m} x_{i j}^{2}}}
$$

where:

- $r_{i j}$ - the normalised value of the $j^{\text {th }}$ indicator for the $i^{\text {th }}$ region,

$x_{i j}$ - the non-normalised value of the $j^{\text {th }}$ indicator for the $i^{\text {th }}$ region.

Step 2: Apply weights to each indicator. As the four indicators are to be weighted evenly, they were each given a weight of 0.25.

At this point, the summation of the values of the four indicators gives us a score between 0 and 1. This is a raw breakdown of the scores for the SSRR index.

Step 3: Determine the ideal $\left(\mathrm{A}^{+}\right)$and negative-ideal $\left(\mathrm{A}^{-}\right)$solutions. As the four indicators are all stimulants, this means that the maximum value was used as the ideal solution and the minimum value was used as the negative ideal solution. These formulas can be written as:

$$
\begin{aligned}
& \mathrm{A}^{+}=\left(v_{1}^{+}, v_{2}^{+}, \ldots, v_{n}^{+}\right) \\
& \mathrm{A}^{-}=\left(v_{1}^{-}, v_{2}^{-}, \ldots, v_{n}^{-}\right)
\end{aligned}
$$

where: $v_{j}^{+}=\operatorname{maximum} v_{i j}$ and $v_{j}^{-}=\operatorname{minimum} v_{i j}$.

Step 4: Calculate the separation measure. This is done by calculating the Euclidean distance between each variable and the ideal and neg- 
ative-ideal solution. The formula for calculating the distance from the ideal solution is:

$$
S_{i^{\star}}=\sqrt{\sum_{j=1}^{n}\left(v_{i j}-v_{j}^{+}\right)^{2}}
$$

The formula for calculating the distance from the negative-ideal solution is:

$$
S_{i^{-}}=\sqrt{\sum_{j=1}^{n}\left(v_{i j}-v_{j}^{-}\right)^{2}}
$$

Step 5: Calculate the relative closeness to the ideal solution. This is done with the following formula:

$$
C_{i^{\star}}=\frac{s_{i^{-}}}{\left(s_{i^{\star}}+s_{i^{-}}\right)}, 0<C_{i^{*}}<1 .
$$

Step 6: Divide the regions into classes based on their results using the arithmetic mean and standard deviation. This is the same method as used by Fura and Wang (2017) and Pawlewicz et al. (2020). The classes are divided by the following criteria:

- Class I - structurally strong rural region when $C_{i} \geq \bar{C}_{i}+S_{C_{i}}$;

- Class II - moderately strong rural region when $\bar{C}_{i} \leq C_{i}<\bar{C}_{i}+S_{C_{i}}$;
- Class III - moderately weak rural region when $\bar{C}_{i}-S_{C_{i}} \leq C_{i}<\bar{C}_{i}$;

- Class IV - structurally weak rural region when $C_{i}<\bar{C}_{i}-S_{C_{i}} ;$ where:

$C_{i}$ - value of the SSRR index calculated with the TOPSIS method,

$\bar{C}_{i}-$ arithmetic mean of the SSRR index,

$S_{C_{i}}$ - standard deviation of the SSRR index.

\section{Results at the national level}

Table 3 shows the descriptive statistics of the SSRR index for the 24 rural regions in Austria from 2008 to 2015. In the last two years, the maximum figure dropped substantially, however, this has not affected the mean in a considerable way. It appears to have affected the standard deviation as this has fallen over the last three years. This likely indicates that the maximum was an individual outlier. The minimum figure has remained relatively stable. Table 4 shows the number and percentage of rural regions in each of the four classes from 2008 to 2015. The number of regions in class 4 has remained stable at four or five each year. There has been a slight change in the number of regions in classes 1 and 2, which was greater than or equal to 50\% from 2012 to 2015 .

Table 3. Descriptive statistics of SSRR index for Austria, 2008-2015.

\begin{tabular}{|l|r|r|r|r|r|r|r|r|}
\hline & 2008 & 2009 & 2010 & 2011 & 2012 & 2013 & 2014 & 2015 \\
\hline Minimum & 0.16 & 0.12 & 0.19 & 0.13 & 0.16 & 0.19 & 0.23 & 0.17 \\
\hline Maximum & 0.80 & 0.81 & 0.79 & 0.74 & 0.83 & 0.80 & 0.67 & 0.59 \\
\hline Mean & 0.42 & 0.35 & 0.42 & 0.39 & 0.42 & 0.48 & 0.44 & 0.41 \\
\hline Standard deviation & 0.16 & 0.16 & 0.15 & 0.16 & 0.15 & 0.12 & 0.12 & 0.10 \\
\hline Coefficient of variation $^{1}$ & 38.09 & 45.71 & 35.71 & 41.02 & 35.71 & 25.00 & 27.27 & 24.39 \\
\hline
\end{tabular}

Source: own calculations using data from Eurostat.

1 This is a synthetic measure of growing/diminishing spatial differences and is calculated by the formula: $\left(S_{C_{i}} / \bar{C}_{i}\right) \times 100$.

Table 4. Number and percentage of rural regions in each class for Austria, 2008-2015.

\begin{tabular}{|l|c|c|c|c|c|c|c|c|}
\hline \multicolumn{1}{|c|}{ Class } & 2008 & 2009 & 2010 & 2011 & 2012 & 2013 & 2014 & 2015 \\
\hline I - Structurally strong & 4 & 5 & 5 & 4 & 4 & 3 & 4 & 3 \\
& $17 \%$ & $21 \%$ & $21 \%$ & $17 \%$ & $17 \%$ & $13 \%$ & $17 \%$ & $13 \%$ \\
\hline II - Moderately strong & 9 & 5 & 7 & 6 & 9 & 9 & 10 & 10 \\
& $38 \%$ & $21 \%$ & $29 \%$ & $25 \%$ & $38 \%$ & $38 \%$ & $42 \%$ & $42 \%$ \\
\hline III - Moderately weak & 6 & 10 & 7 & 10 & 7 & 8 & 5 & 7 \\
& $25 \%$ & $42 \%$ & $29 \%$ & $42 \%$ & $29 \%$ & $33 \%$ & $21 \%$ & $29 \%$ \\
\hline IV - Structurally weak & 5 & 4 & 5 & 4 & 4 & 4 & 5 & 4 \\
& $21 \%$ & $17 \%$ & $21 \%$ & $17 \%$ & $17 \%$ & $17 \%$ & $21 \%$ & $17 \%$ \\
\hline
\end{tabular}

Source: own calculations using data from Eurostat. 
Figure 2 shows the geographical distribution of the SSRR index for 2008 and 2015 for Austria. The structurally strong and moderately strong rural regions are located in the eastern and south-eastern parts of the countries. The structurally weak rural regions are located in the south, near the border with Italy, which confirms our initial assumption/ supposition that the border mountain areas seem
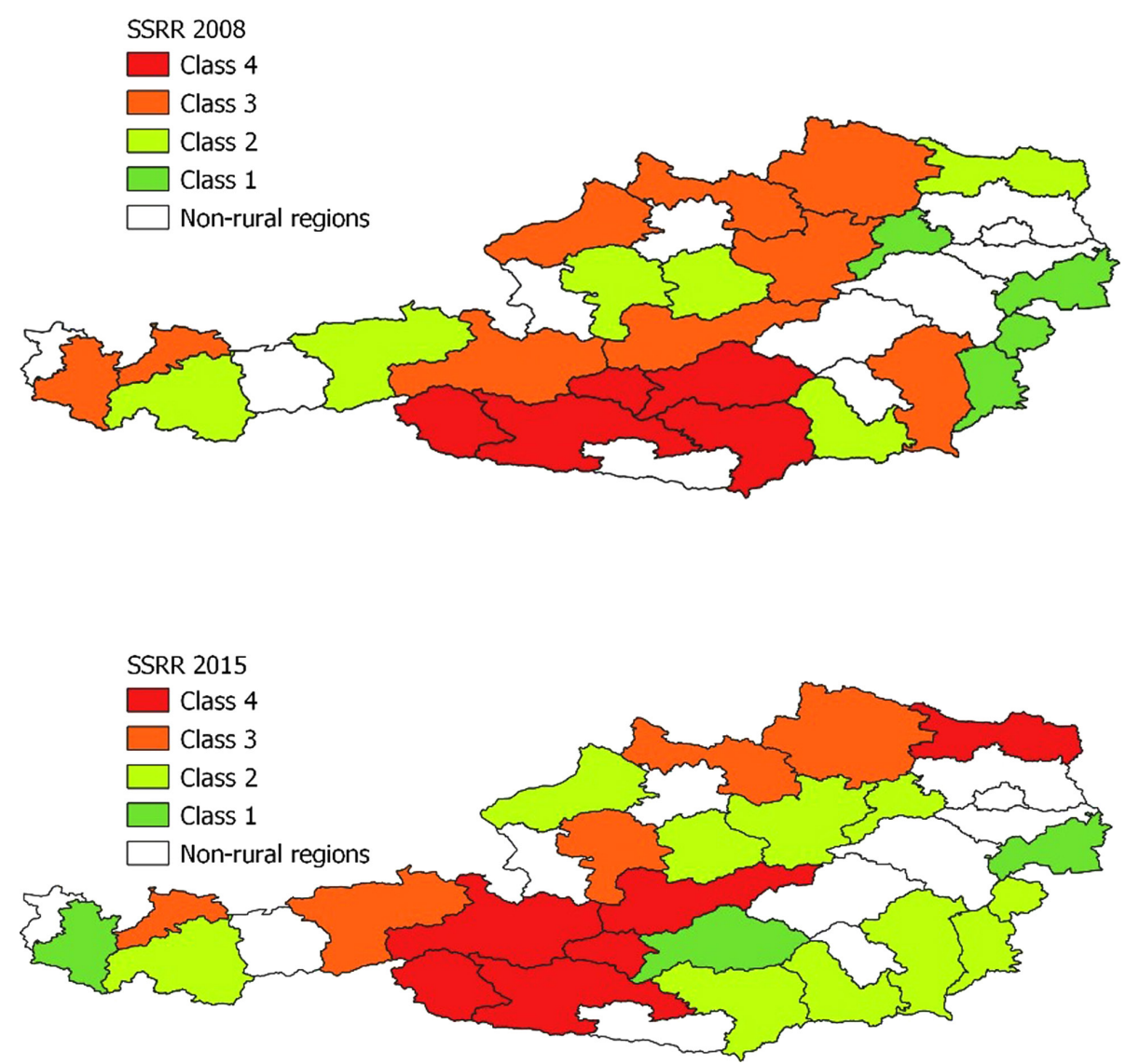

Fig. 2. Classification of rural regions based on SSRR index for Austria in 2008 and 2015. Source: own calculations using data from Eurostat.

Table 5. Descriptive statistics of SSRR index for Portugal, 2008-2015.

\begin{tabular}{|l|r|r|r|r|r|r|r|r|}
\hline & 2008 & 2009 & 2010 & 2011 & 2012 & 2013 & 2014 & 2015 \\
\hline Minimum & 0.14 & 0.36 & 0.34 & 0.22 & 0.10 & 0.13 & 0.24 & 0.12 \\
\hline Maximum & 0.77 & 0.61 & 0.68 & 0.72 & 0.89 & 0.56 & 0.82 & 0.78 \\
\hline Mean & 0.36 & 0.49 & 0.48 & 0.40 & 0.47 & 0.36 & 0.57 & 0.45 \\
\hline Standard deviation & 0.16 & 0.07 & 0.10 & 0.14 & 0.20 & 0.14 & 0.16 & 0.17 \\
\hline Coefficient of variation & 44.44 & 14.28 & 20.83 & 35.00 & 42.55 & 38.89 & 28.07 & 37.78 \\
\hline
\end{tabular}

Source: own calculations using data from Eurostat.

Table 6. Number and percentage of rural regions in each class for Portugal, 2008-2015

\begin{tabular}{|l|c|c|c|c|c|c|c|c|}
\hline \multicolumn{1}{|c|}{ Class } & 2008 & 2009 & 2010 & 2011 & 2012 & 2013 & 2014 & 2015 \\
\hline I - Structurally strong & 2 & 4 & 2 & 3 & 3 & 4 & 3 & 2 \\
& $13 \%$ & $25 \%$ & $13 \%$ & $19 \%$ & $19 \%$ & $25 \%$ & $19 \%$ & $13 \%$ \\
\hline II - Moderately strong & 5 & 3 & 6 & 4 & 5 & 3 & 6 & 7 \\
& $31 \%$ & $19 \%$ & $38 \%$ & $25 \%$ & $31 \%$ & $19 \%$ & $38 \%$ & $44 \%$ \\
\hline III - Moderately weak & 7 & 7 & 5 & 6 & 7 & 5 & 4 & 5 \\
& $44 \%$ & $44 \%$ & $31 \%$ & $38 \%$ & $44 \%$ & $31 \%$ & $25 \%$ & $31 \%$ \\
\hline IV - Structurally weak & 2 & 2 & 3 & 3 & 1 & 4 & 3 & 2 \\
& $13 \%$ & $13 \%$ & $19 \%$ & $19 \%$ & $6 \%$ & $25 \%$ & $19 \%$ & $13 \%$ \\
\hline
\end{tabular}

Source: own calculations using data from Eurostat. 
particularly affected by structural weaknesses. On the other hand, the values of variation coefficients indicate a general tendency to equalise spatial differences in the structural strength of the Austrian rural regions as seen in the years 2012-2015.

Table 5 shows descriptive statistics of the SSRR index for the 16 rural regions in Portugal from 2008 to 2015 . There were some changes during the period, however, other than the mean, the statistics in 2008 and 2015 were similar. This would indicate that although there were some variations, things have remained consistent. Table 6 shows the number and percentage of rural regions in each of the four classes from 2008 to 2015. In general, there were more regions in classes 3 and 4 (moderately weak and structurally weak). The number of regions classified as structurally weak tended to be 2 or 3 . The two years with the highest proportion of regions in class 1 and 2 were 2014 and 2015, which could be an indication that the situation has been improving.

Figure 3 shows the geographical distribution of the SSRR index for 2008 and 2015 for Portugal. The rural regions that are in classes 1 and 2, and have improved over the time, are the regions on the coast and the regions that are located on the Lisbon-Porto axis. The rural regions that are in classes 3 and 4 are those that are located on the inland and bordered with Spain. This means that the process of 'littoralisation', mentioned at the beginning of our study, is still (and even more) clearly visible in Portugal.

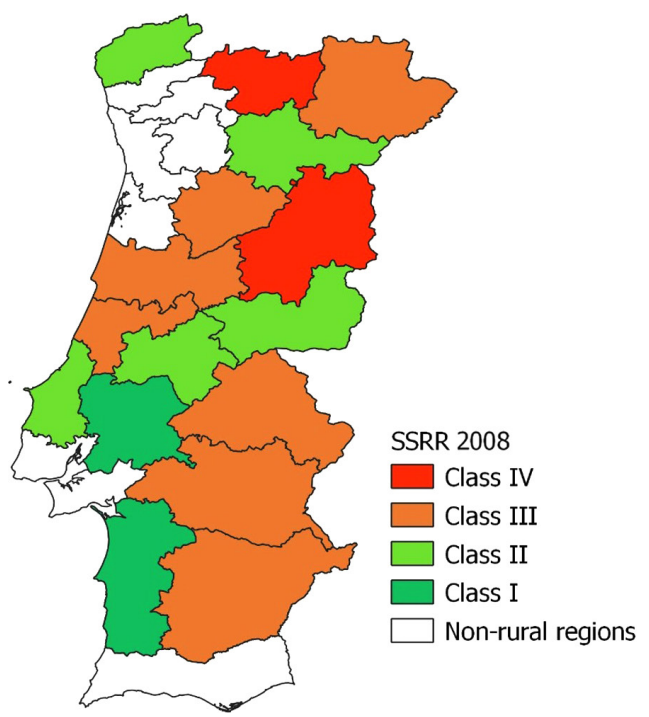

\section{Breakdown of results for two structurally weak rural regions located in each country}

The previous section presents the values and geographical distribution of the SSRR index for both countries. The purpose of this section is to delve further into the data for one structurally weak rural region from each country. These are Osttirol in Austria and Alentejo Central in Portugal. The regions have been chosen as they have both been classified as structurally weak for the majority of years from 2008 to 2015. Analysis at the local level is important to provide a clearer understanding of the dynamics of structural weakness.

Osttirol is a rural region located in south Austria on the border with Italy. Between 2008 and 2015, it has seen a steady decline in population density, going from 25.0 inhabitants per $\mathrm{km}^{2}$ to 24.4. Meanwhile, the figure for Austria as a whole increased from 100.9 to 104.9. The SSRR index classified Osttirol as structurally weak for all 8 years from 2008 to 2015. Alentejo Central is a region in Portugal that borders Spain. It is a sparsely populated region with only 21.5 inhabitants per $\mathrm{km}^{2}$ in 2015, compared to 112.3 inhabitants per $\mathrm{km}^{2}$ for the whole of Portugal. Alentejo Central was classified as structurally weak for 6 of the 8 years from 2008 and 2015.

Figure 3 provides a raw breakdown of the values for the four indicators, post-weighted

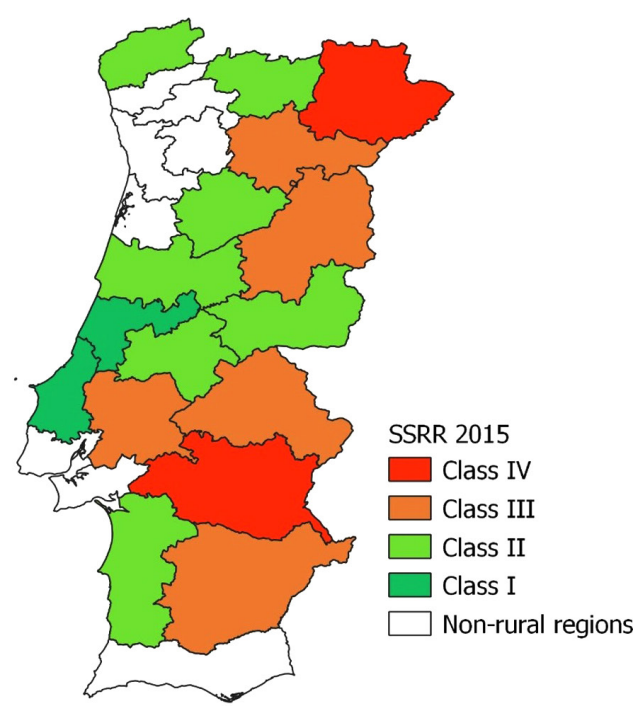

Fig. 3. Classification of rural regions based on SSRR index for Portugal in 2008 and 2015. Source: own calculations using data from Eurostat. 
normalisation, over the period 2008 to 2015 for Osttirol. This is the result after step 2 of the TOPSIS process described above. As can be seen, GDP per capita and the employment rate has remained consistent over the time period. The two variables that are more volatile are the net business creation and crude rate of net migration. The crude rate of net migration has been the lowest of the four indicators. This would imply that people do not consider Osttirol as a viable option in terms of a place to live. This may be to do with perceived lack of opportunities or better opportunities in urban areas.

Figure 4 provides a raw breakdown of the values for the four indicators, post-weighted normalisation, over the period 2008 to 2015 for Alentejo Central. Similar to Osttirol, the values for GDP per capita and the employment rate have remained relatively consistent over the years. The value for migration has deteriorated severely over the years and this indicates a strong shift for the population leaving the region. Net business creation was weak at the start, which improved during the middle years but has since decreased.

\section{Discussion and conclusions}

Rural development is a complex, multi-dimensional process and it is important to find an appropriate measure for understanding it. The formal model proposed by Petrick (2013) provides us with an understanding of how some

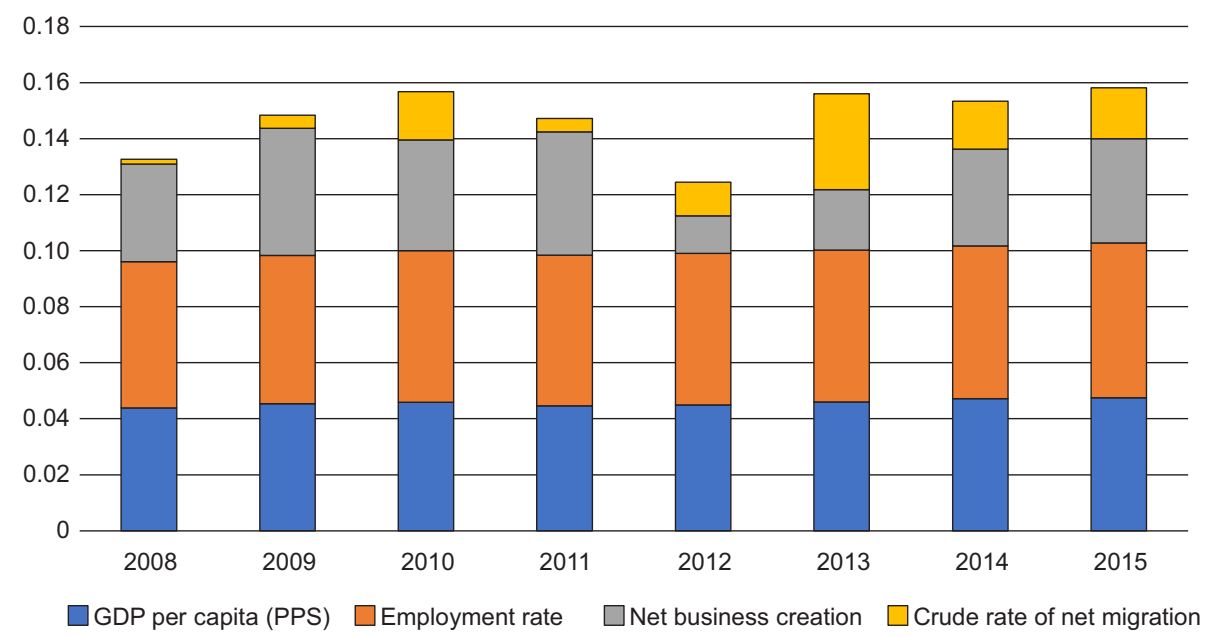

Fig. 4. Raw breakdown for the indicators of SSRR index for Osttirol, 2008 to 2015. Source: own calculations using data from Eurostat. 0.25

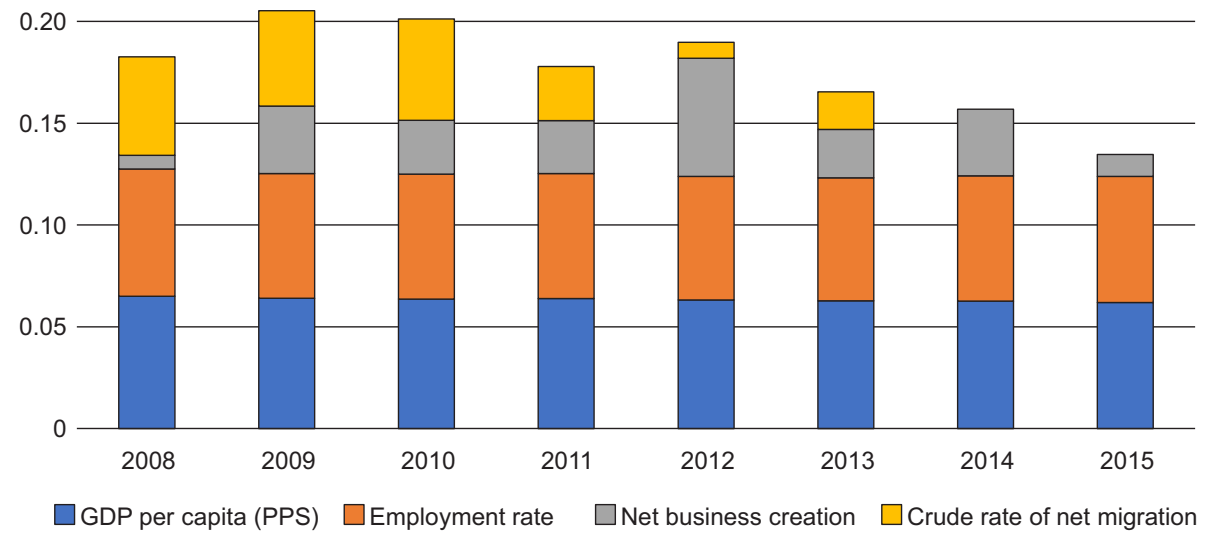

Fig. 5. Raw breakdown for indicators of SSRR index for Alentejo Central, 2008 to 2015. Source: own calculations using data from Eurostat. 
rural regions can be trapped in a cycle of decline, while others can be thriving. The SSRR index developed in this paper provides us with a convenient tool to classify regions based on their structural strength. This index can be used for regions across different countries and can be measured on an annual basis.

From the results of the SSRR index at the national level, we can draw some interesting conclusions. Portugal still faces regionalisation with inland regions being more likely to be structurally weak. The structurally strong rural regions and the rural regions that saw an improvement in structural strength are the regions on the coast or near the Lisbon-Porto axis. This is likely the result of increasing influence of Lisbon as the centre of the country, and the importance of it as the economic core of the country.

The regionalisation in Austria has shifted. Although eastern regions were once considered the peripheral, less developed parts of the country, this has changed. Now the rural regions in the east and south-east are structurally stronger. This is possibly due to the proximity to Vienna. Another possible explanation for this shift is the EU enlargement in 2004. The countries on the eastern border with Austria (Slovenia, Hungary and Slovakia) joined the EU, which opened new trade routes and a large market for these rural regions. The EU supporting policy measures also facilitated this process.

Positive trends are not so visible at the level of the weakest rural regions, regardless of their location. Although situated in very different countries, the two structurally weak rural regions we analysed, Osttirol in Austria and Alentejo Central in Portugal, are both stuck in a circle of decline for the same reasons. Both face the challenges of outmigration and lack of investment. These issues can be tackled by active rural residents, that is, as per Petrick (2013), the mobile population needs to remain in the area and the immobile population needs to invest locally. In game theory, this is considered a coordination problem. If a region is stuck in the circle of decline, this is the less optimal equilibrium position; this is likely because this solution is 'risk dominant' (Harsanyi, Selten 1988). That is to say, participants choose the less optimal strategy if they consider it less risky. This happens when there is considerable uncertainty regarding the strategy that the other player will choose. In our example, this means the immobile will not invest if they feel there is a high probability that the mobile will move and the mobile will leave if they feel there is a high probability that the immobile will not invest in the region. Further research needs to be done on the reasons that the population in some rural regions choose the less optimal solution and what can be done to incentivise optimising behaviour on part of the rural population.

The case of eastern and south-eastern Austrian rural regions show that the 'vicious circle' of a declining rural region can be broken if a 'window of new opportunities' opens (like the EU enlargement and opening the borders to the neighbouring countries). The situation of Portuguese rural regions seems worse (which is confirmed by the values of the SSSR index introduced in this article). They cannot expect similar large-scale shifts in their geopolitical and economic position. This means that the role of national and local governance institutions seems crucial in overcoming structural weakness of such rural regions.

\section{Acknowledgements}

This research has received funding from the European Union's Horizon 2020 research and innovation program under the Marie Skłodowska Curie grant agreement number 721999 .

\section{References}

Abreu I., Nunes J.M., Mesias F.J., 2019. Can rural development be measured? Design and application of a synthetic index to Portuguese municipalities. Social Indicators Research 145: 1107-1123, https://doi.org/10.1007/s11205019-02124-w

Fura B., Wang Q., 2017. The level of socioeconomic development of EU countries and the state of ISO 14001 certification. Quality \& Quantity 51(1): 103-119.

Good D., 1981. Economic integration and regional development in Austria-Hungary, 1867-1913. In Bairoch P., Lévy-Leboyer M. (eds), Disparities in economic development since the industrial revolution. Macmillan Press Ltd., London: 137-150.

Harsanyi J.C., Selten R., 1988. A general theory of equilibrium selection in games. MIT Press, Boston.

Hwang C., Yoon K., 1981. Multiple attribute decision making: Methods and applications: A state of the art survey, Springer, Berlin.

Jakubowski A., 2018. Convergence or divergence? Multidimensional analysis of regional development in the new European Union member states. Barometr Regionalny 16(1): 31-40. 
Kilper H. (ed.), 2009. New disparities in spatial development in Europe. Springer, Berlin Heidelberg.

Lois-González R., 2007. Designation of marginal and peripheral areas in the geography of different countries. A comparative approach. In: Jones G., Leingruber W., Nel E. (eds), Issues in geographical marginality. Papers presented during the Commission Meetings 2001-2004. Rhodes University, Grahamstown, South Africa: 76-81.

Malinowski M., 2019. Institutional infrastructure and sustainable development: Analysis of eastern Poland districts. Studia Ekonomiczne 384: 51-69.

Mayer J., 1981. Regional development in Portugal (19291977): An assessment. In Bairoch P., Lévy-Leboyer M. (eds), Disparities in economic development since the industrial revolution. Macmillan Press Ltd., London: 331-345.

Michalek J., Zarnekow N., 2012. Application of the Rural Development Index to analysis of rural regions in Poland and Slovakia. Social Indicators Research 105: 1-37, https:/ / doi.org/10.1007/s11205-010-9765-6

Nash J., 1951. Non-cooperative games. The Annals of Mathematics 54(2): 286-295.
Neufeld M., 2017. Eine Frage des Maßstabs? Zum Verhältnis von Kohäsion und Polarisierung in Europa. Europa Regional 23(4): 15-29.

OECD 2006. The new rural paradigm: Policies and governance. OECD, Paris.

OECD 2008. Handbook on constructing composite indicators. Methodology and user guide. OECD, Paris.

Pawlewicz K., Senetra A., Gwiaździńska-Goraj M., Krupickaitè D., 2020. Differences in the environmental, social and economic development of Polish-Lithuanian trans-border regions. Social Indicators Research, 147(3): 1015-1038 https://doi.org/10.1007/s11205-019-02179-9

Petrick M., 2013. Reversing the rural race to the bottom: An evolutionary model of neo-endogenous rural development. European Review of Agricultural Economics 40(4): 707-735, https://doi.org/10.1093/erae/jbt019

Stiglitz J., Fitoussi J., Durand M., 2018. Beyond GDP: Measuring what counts for economic and social performance. OECD Publishing, Paris.

Wink R., Kirchner L., Koch F., 2016. Wirtschafltliche Resilienz in deutschsprachigen Regionen. Springer Gabler, Wiesbaden. 